\title{
Research on the Relationship between Human Resource Management Activities and Enterprise Performance Based on the Supervised Learning Model
}

\author{
Chan Sun ${ }^{1}$ and Xiaojuan Li $\mathbb{1}^{2}$ \\ ${ }^{1}$ School of Business, Hunan International Economics University, Changsha 410000, Hunan, China \\ ${ }^{2}$ School of Business Administration, Hunan University of Finance and Economics, Changsha 410205, Hunan, China \\ Correspondence should be addressed to Xiaojuan Li; lixiaojuan@hufe.edu.cn
}

Received 12 October 2021; Accepted 27 October 2021; Published 28 November 2021

Academic Editor: Gengxin Sun

Copyright (c) 2021 Chan Sun and Xiaojuan Li. This is an open access article distributed under the Creative Commons Attribution License, which permits unrestricted use, distribution, and reproduction in any medium, provided the original work is properly cited.

\begin{abstract}
HRMS is a very critical tool for companies. The recruitment text contains rich information that can provide strong information support for the company's recruitment work and also improve the efficiency of job seekers in finding job opportunities. To this end, for the problem of multilabel text classification of recruitment information, this paper provides two algorithms for multilayer classification based on supported SVM. First, the same learning subclass method is used for text sorting subclass acquisition, and then, the class of the text is determined. Second, the hemispherical support SVM is used to find the smallest hypersphere in the feature space that contains the most text of that class and segment the text of that class from other texts. For the text to be classified, the distance from it to the center of each hypersphere is used to determine the class of the text. Experimental results on recruitment data demonstrate that the algorithm in this paper has a high check-all rate, check-accuracy rate, and F1. And, the relationship between HRM activities and corporate performance is discussed.
\end{abstract}

\section{Introduction}

More and more data are generated by the development of enterprises, and with such a huge amount of data, it is simply impossible to implement human efforts to manage and analyze the data, thus giving birth to information management systems. Information management system [1-3] is a kind of management software with functions such as data collection and database creation and data management, which can manage and analyze a large amount of data in a unified way. HRMS combines human resource management and information technology, which is not only an information processing tool but also a resource management specification whose main purpose is to standardize the business processes of HR departments, centralize HR information, and improve the transparency of HR management through the system [4]. Such a huge amount of data has exceeded the processing capacity of traditional HR management systems, thus making it impossible to properly manage and analyze data, which is described as "data-rich, but information-poor" $[5,6]$. This situation is described as "data-rich but information-poor." Moreover, most of the enterprise-level HR management systems have not been given full play, only collecting and storing data, but not effectively managing and analyzing the data and information, which not only wastes the limited resources of the enterprise but also loses the opportunity to use big data for rapid development $[7,8]$.

In the context of the traditional HR management system cannot meet the needs of enterprise big data, in order to make the system work properly, it is then necessary to artificially perform certain screening process on the massive data, so as to reduce the data volume level of big data, but this processing method seems to be back to the old era of manual data processing, which seriously hinders the improvement of work efficiency. For this reason, data mining 
[9] has been proposed to reduce the amount of data to be processed. The purpose of data mining is to analyze the large amount of raw data and discover the important data patterns and finally convert the raw data into useful information and knowledge.

Data mining is the use of various techniques and statistical methods to mine useful information and knowledge from large amounts of data [10].

\section{Related Work}

Human resource management system is an important tool for enterprise management and plays an important role in enterprise development, which has been generated at the present time. With the advent of the era of big data in the 21st century, it has brought some impacts and changes to HRM [11-13].

Jiang et al. [14] analyzed in detail the important role of data mining in HRM for talent recruitment, talent management, talent loss prevention, and improving HR precision management. Zhang et al. [15] demonstrated the capability of data mining in improving the quality of decision-making process in the HRM system. Rai et al. [16] analyzed and implemented the application of data mining in separation management. Xia et al. [17] proposed a knowledge discovery model that helps to support companies in predicting the future performance of their employees and then assigning the right people to the right positions and projects. Martínez-Ferrero et al. [18] proposed a fuzzy clustering method based on adaptive genetic algorithm, which provides effective data analysis for employee performance appraisal in modern corporate HRM. Bajo et al. [19] used artificial neural networks for turnaround prediction, knowledge-based search engine for candidate search, genetic algorithm for staff scheduling, text mining for HR sentiment analysis, resume data collection and information extraction, and employee self-service with interactive voice response. Trauth et al. [20] designed an improved algorithm based on support vector regression for HR demand forecasting in enterprises with good practical reference value. Walmsley [1] applied extreme gradient boosting (XGBoost) technique to predict employee turnover in order to solve the turnover problem and demonstrated its higher accuracy in predicting employee turnover compared to other supervised classifier algorithms. Brito and Oliveira [21] analyzed the factors affecting employee retirement based on work-life profiles and used machine learning methods to create a retirement prediction model that could provide a solution to the human resource outflow problem.

\subsection{Data Acquisition}

2.1.1. The Nature of Recruitment Content Classification. It is the process of classifying information about a job set in a text form and the process of automatic classification of documents using text, which is one or more predefined categories in the document. In this paper, text-based classification techniques about machine learning and statistical methods have become the main techniques in the area. The idea of classification is based on various labeled texts, on a relational model between features and document categories, and then on a relational model to determine the category to which the test text belongs [6, 22-25]. Text classification is divided into two processes: learning and testing. As shown in Figure 1, the learning process begins with preprocessed text; then, using any mathematical description, the previously processed text is represented as a computerized form of recognizable data, which is then represented with the help of a classification algorithm that receives training text data and then receives the appropriate classifier. As shown in Figure 2, the testing process is the process of preprocessing the text and the mathematical description after recognizing it by the classifier to obtain the text category.

2.1.2. Data Acquisition. The data used in this article is for the 58 Tongcheng open source data $[11,26]$, as well as other open source data on the site; the link is https://download. csdn.net/download/huazi99/11964169https:/download. csdn.net/download/weixin_\%2044028406/15801929.

2.1.3. Data Preprocessing. This section will introduce some knowledge about text classification, presenting the techniques used in the following experiments.

2.1.4. Chinese Word Splitting. In natural language, words are a relatively important presence, and most words have semantic information. At the same time, words are also the main components of a complete sentence. Because in English, an English sentence is composed of English words separated by the use of space characters, the division is relatively simple; whereas Chinese sentences are composed of each individual word as a unit, and Chinese phrases consist of a series of consecutive words, each without a separator. Therefore, the division into Chinese is more difficult than that of English [26-31]. There are three ways: string matching-based segmentation, statistics-based Chinese segmentation, and comprehension-based Chinese segmentation.

2.1.5. Removing Deactivated Words. Deactivators are words in Chinese text that do not contain actual semantic meaning and do not have a certain degree of distinction. In the text information, with the presence of stop words, the whole text looks more fluent, but in the text analysis, the presence of stop words interferes with it; these stop words not only do not contain effective information and cannot accurately express the meaning of the sentence but also may have a suppressive effect on other characteristic words.

2.1.6. Feature Selection. After the text data are divided into Chinese words and deactivated words are removed, many words will be obtained and feature selection is needed. In order to further improve the model and algorithm, good feature selection has the most important value. The methods of feature selection are cardinality statistics [32], mutual 


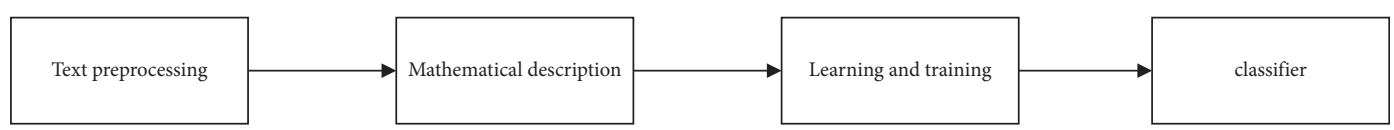

Figure 1: Text classification training process.

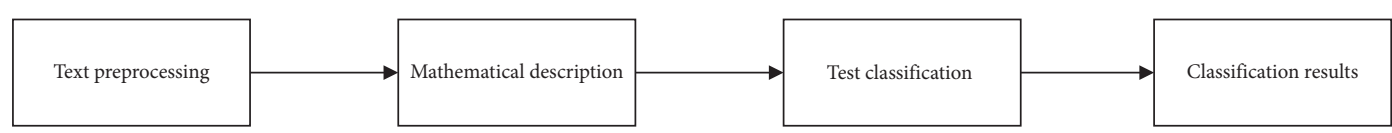

Figure 2: Text classification test process.

information method [33], TF-IDF method [34], and bag-ofwords model [35].

\subsection{Multilabel Text Classification}

2.2.1. Hyperspherical SVM. Given a training sample set of class $\left\{x_{i}\right\}_{i=1}^{l}$ and a kernel function $k\left(x_{i}, x_{j}\right)$, where $x_{i} \in R^{n}$, $k\left(x_{i}, x_{j}\right)$ corresponds to the inner product in the feature space, i.e., $K\left(x_{i}, x_{j}\right)=g\left(x_{i}\right) \cdot g\left(x_{j}\right)$ If there are some examples of remote mappings, then we find the minimum HILER that contains most of the examples. However, when we are not sure if there are remote mappings of samples,

$$
\begin{aligned}
& \min \quad F\left(R, a, \xi_{i}\right)=R^{2}+\frac{1}{v l} \sum_{i} \xi_{i}, \\
& \text { s.t. } \quad\left\|g\left(x_{i}\right)-a\right\|^{2} \leq R^{2}+\xi_{i}, \\
& \xi_{i} \geq 0, \quad i=1,2, \ldots, l .
\end{aligned}
$$

To solve the above constraining optimization problem, the following Lagrangian function can be constructed:

$$
\begin{aligned}
L\left(R, a, \beta, \gamma, \xi_{i}\right)= & R^{2}+\frac{1}{v l} \sum_{i=1}^{l} \xi_{i}-\sum_{i=1}^{l} \beta_{i} \\
& \cdot\left\{R^{2}+\xi_{i}-\left\|g\left(x_{i}\right)-a\right\|^{2}\right\}-\sum_{i=1}^{l} \gamma_{i} \xi_{i},
\end{aligned}
$$

where $\beta_{i} \geq 0$ is the Lagrangian multiplier of the class. To obtain the minimum of equation (2),

$$
\begin{aligned}
\frac{\partial L}{\partial R} & =2 R\left(1-\sum_{i=1}^{l} \beta_{i}\right)=0 \Rightarrow \sum_{i=1}^{l} \beta_{i}=1, \\
\frac{\partial L}{\partial \xi_{i}} & =\frac{1}{v l}-\beta_{i}-\gamma_{i}=0 \Rightarrow 0 \leq \beta_{i} \leq \frac{1}{v l}, \quad i=1,2, \ldots, l, \\
\frac{\partial L}{\partial a} & =-\sum_{i=1}^{l} 2 \beta_{i}\left(g\left(x_{i}\right)-a\right)=0 \Rightarrow a \\
& =\sum_{i=1}^{l} \beta_{i} g\left(x_{i}\right), \quad i=1,2, \ldots, l .
\end{aligned}
$$

Substituting equations (1)-(3) into equation (4), the pairwise optimization problem is

$$
\begin{aligned}
\max \quad L\left(\beta_{i}\right) & =L\left(R, a, \beta, \gamma, \xi_{i}\right) \\
& =\sum_{i=1}^{l} \beta_{i} K\left(x_{i}, x_{i}\right)-\sum_{i, j=1}^{l} \beta_{i} \beta_{j} K\left(x_{i}, x_{j}\right) \\
\text { s.t. } \quad \sum_{i} \beta_{i} & =1, \quad 0 \leq \beta_{i} \leq \frac{1}{v l}, i=1,2, \ldots, l .
\end{aligned}
$$

According to equation (4), a weighting factor $\beta_{i}$ is linearly composed of

$$
a=\sum_{i} \beta_{i} g\left(x_{i}\right)
$$

If $\beta_{i}>0$, then the corresponding sample is called the support vector.

If it is $0 \leq \beta_{i} \leq 1 / v l$, the corresponding sample is located near the surface of the pole.

If $\beta_{i}=1 / v l$, the corresponding sample is called an outlier or noise sample.

2.2.2. Improvement Algorithm. For the sample $x$ to be classified, then determine whether the sample $x$ belongs to class $m$ according to $d_{m}(x)$ and $R_{m}$ :

$$
\begin{aligned}
{\left[d_{m}(x)\right]^{2} } & =\left\|g(x)-a_{m}\right\|^{2} \\
& =g(x)-\sum_{i} \beta_{i}^{m} g\left(x_{i}^{m}\right) \|^{2} \\
& =K(x, x)+\sum_{i, j} \beta_{i}^{m} \beta_{j}^{m} K\left(x_{i}^{m}, x_{j}^{m}\right)-2 \sum_{i} \beta_{i}^{m} K\left(x, x_{i}^{m}\right) .
\end{aligned}
$$

If $d_{m}(x) \leq R_{m}$ satisfies one, then calculate the affiliation of $x$ belonging to class $m$ from

$$
r_{m}=\frac{R_{m}}{d_{m}(x)}
$$

According to equation (7), the category to which sample $x$ belongs can be determined:

$$
r=\max _{m} r_{m}
$$

Our algorithm is described in detail as follows :

Step 1: for $X$, we calculate according to equation (6), $d_{m}(x)(m=1,2, \ldots, N)$. 
Step 2: if one or more classes meet $d_{m}(x) \leq R_{m}$, sample $x$ is marked as class $m$ goes to step 4 .

Step 3: calculate $r_{m}$ use equation (7) and $R$ use equation (8). $X$ is labeled class $m\left\{m \mid r_{m} \geq r, m=1,2, \ldots, N\right\}$.

Step 4: end.

\section{Experiments}

The experiments were conducted on collected 58 Tongcheng data with five categories and 685 job postings, each with a class number less than 4 . Four hundred and forty five articles were used as training samples (Table 1). The feature dimension is reduced by using information gain and feature weight of each word.

Precision, recall, and F1 are used to evaluate the classification performance. The definitions are as follows:

$$
\begin{aligned}
d_{m}(x) & (m=1,2, \ldots, N), \\
\operatorname{precision}(P) & =\frac{N_{c}}{N_{a}}, \\
\operatorname{recall}(R) & =\frac{N_{c}}{N_{r}} \\
F 1 & =\frac{2 * P * R}{P+R} .
\end{aligned}
$$

$N_{r}$ is the actual number of classes for each sample:

$$
\text { Definition 2: Average Precision }(\mathrm{AP})=\frac{\sum P}{n} \text {. }
$$

If $n$ is the number of all test samples, then the macro is the mean average accuracy (MAAP) [36]. If $n$ is the number of test samples with the same number, then it is called microaverage accuracy (MIAP):

$$
\text { Definition 3: Average Recall }(\mathrm{AR})=\frac{\sum R}{n} \text {. }
$$

The implementation of the algorithm refers to [12], and the parameters of the algorithm are set as shown in Table 2.

The classification results are shown in Tables 3-5.

The experimental results demonstrate that, in this paper, the same approach applies to smaller training modules. Our method technique applies to a wider and broader range of educational materials.

In order to obtain a good human resource management effect, it is also necessary to make the effect of human resource management to be maximized through an appropriate performance appraisal system; it can be said that performance appraisal also has the following important significance in human resource management, as shown in Figure 3, and it can be concluded that having different academic qualifications and performance appraisal is an important basis for personnel appointments. Through performance appraisal, the situation of employees can be
TABle 1: Training set.

\begin{tabular}{lccccc}
\hline Categories & IT & Service & Sales & Transportation & Engineering \\
\hline Training & 18 & 58 & 69 & 82 & 24 \\
Test & 24 & 21 & 86 & 56 & 31 \\
\hline
\end{tabular}

TABLE 2: Algorithm parameter settings.

\begin{tabular}{lcccc}
\hline Algorithm & FDAGSVM algorithm & MC & 1-rMC & Our method \\
\hline $\mathrm{c}$ & 40 & 200 & 100 & - \\
$\gamma$ & 0.05 & 0.005 & 0.005 & 0.01 \\
$\varepsilon$ & - & 0.01 & 0.1 & - \\
$k$ & 0.2 & 0.9 & 0.64 & - \\
$v$ & - & - & - & 0.65 \\
\hline
\end{tabular}

TABLE 3: Comparison of different algorithms.

\begin{tabular}{lccc}
\hline Algorithm & MA (\%) & AR (\%) & MF (\%) \\
\hline FDAGSVM & 63.83 & 55.24 & 62.21 \\
1-a-1MC & 78.96 & 77.34 & 74.83 \\
1-a-rMC & 75.94 & 74.04 & 78.98 \\
Our method & $7^{*} .36$ & 73.61 & 70.47 \\
\hline
\end{tabular}

TABLE 4: Comparison of different algorithms.

\begin{tabular}{lcccc}
\hline Algorithm & Tags & MP (\%) & MR (\%) & MF (\%) \\
\hline \multirow{3}{*}{ SVM } & 1 & 65.32 & 63.76 & 64.21 \\
& 2 & 57.37 & 56.33 & 56.57 \\
& 3 & 55.66 & 54.57 & 55.38 \\
\hline \multirow{3}{*}{ 1-a-1MC } & 1 & 77.32 & 80.19 & 78.18 \\
& 2 & 81.41 & 48.08 & 58.85 \\
& 3 & 100.00 & 33.33 & 50.00 \\
\hline \multirow{3}{*}{ 1-a-rMC } & 1 & 73.86 & 80.19 & 75.44 \\
& 2 & 74.62 & 44.23 & 53.48 \\
& 3 & 75.00 & 50.00 & 60.00 \\
\hline \multirow{3}{*}{ Our } & 1 & 71.94 & 75.47 & 73.11 \\
& 2 & 76.28 & 50.00 & 58.59 \\
& 3 & 66.67 & 66.67 & 66.67 \\
\hline
\end{tabular}

TABLE 5: Comparison of training and testing time.

\begin{tabular}{lcc}
\hline Algorithm & Training time (s) & Test time (s) \\
\hline SVM & 31 & 32 \\
1-1MC & 39 & 29 \\
rMC & 82 & 29 \\
Our & 9 & 11 \\
\hline
\end{tabular}

evaluated, so that the working attitude and status of each employee can be clarified, and good support for the arrangement of personnel positions can be provided.

As shown in Figure 4, the average salary of employees can be used to control the application of HRMS for staff scheduling and job promotion, so that the role of HRM can be fully utilized. In order to give full play to the role of talent, enterprises are required to have a detailed understanding of the work of employees in the process of hiring, through the performance appraisal system to clarify the attitude and work situation of employees during the work period, to conduct an 


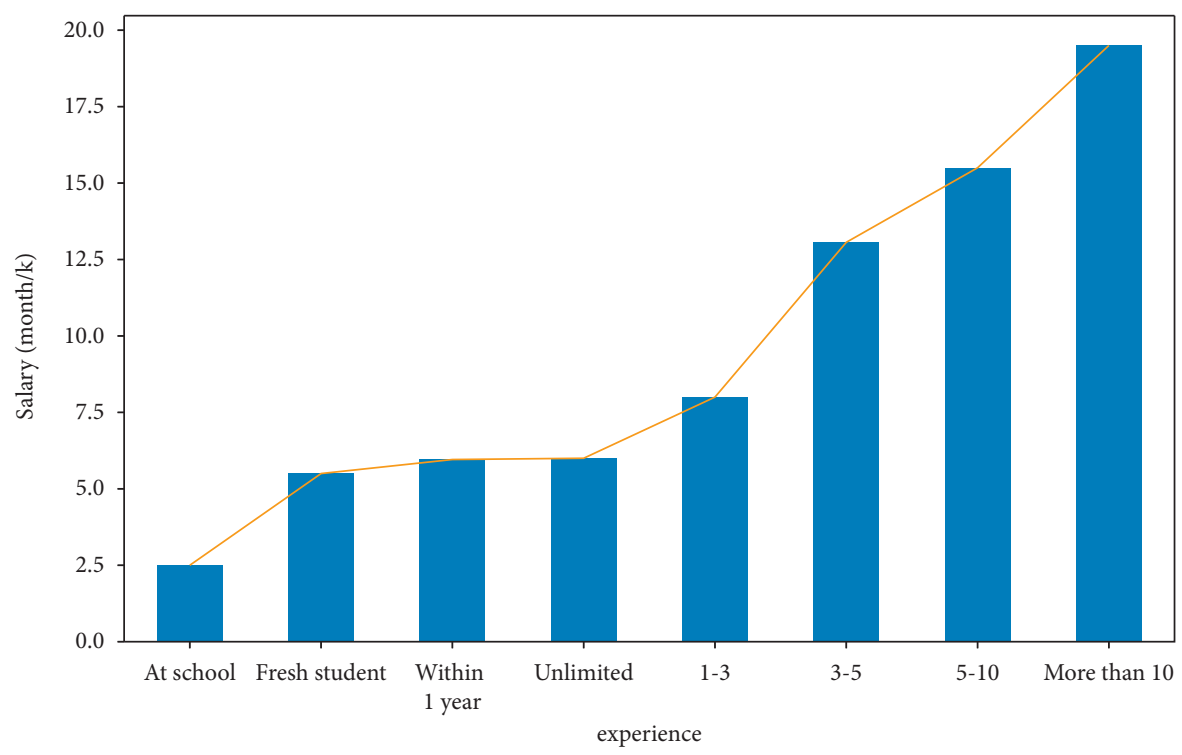

FIGURE 3: Salary of different educations.

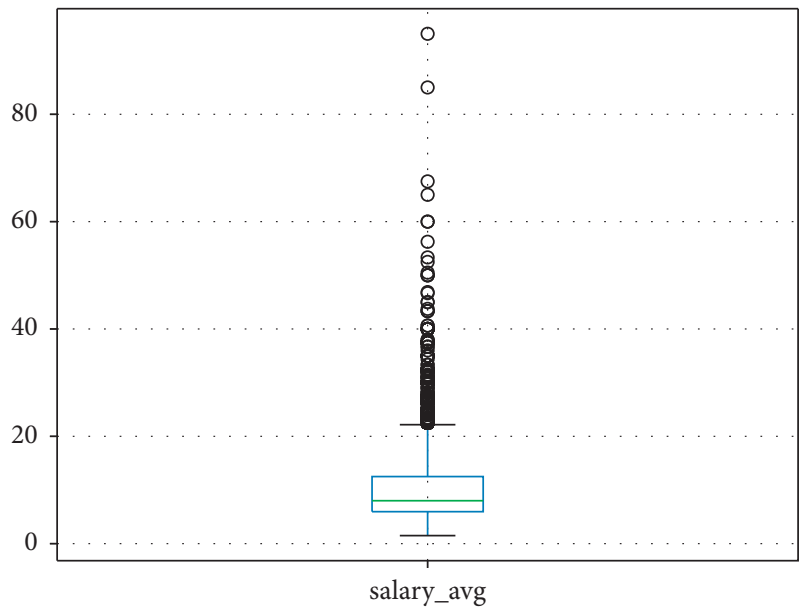

Figure 4: Average employee salary.

objective comparative evaluation of employees, and to provide sufficient reference basis for employee promotion, so that enterprise human resource management can be reasonably realized. Therefore, performance appraisal has a very important significance in the process of human resource management job scheduling and also has an important significance for the optimal allocation of human resources.

As shown in Figure 5, such a performance appraisal is an important mechanism for rewarding salary, and in the modern enterprise management project, it is necessary to follow the principle of fairness and efficiency in salary allocation. Through the application of the performance appraisal system, it is possible to reasonably allocate the salary based on the actual working conditions of the employees and to guarantee the reasonableness of the salary allocation, which is also an important means to guarantee the employees' motivation and enthusiasm for work.

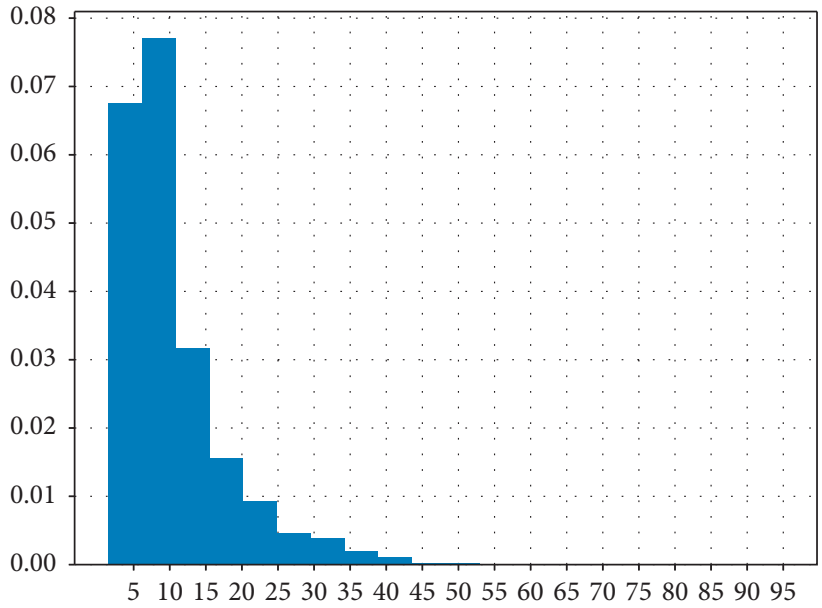

FIgURE 5: Enterprise human resource utilization.

\section{Discussion and Analysis}

In the process of constructing the performance appraisal system of modern enterprises, the purpose of the appraisal needs to be clear first, and on this basis, a targeted appraisal system should be constructed. The object of performance appraisal in enterprises is employees, so it is also necessary to combine the performance and work attitude of employees on the basis of a reasonable calculation of performance appraisal results and, on this basis, to carry out targeted management of employees so that the effectiveness of performance appraisal can be given full play. In the modern enterprise, human resource management work also needs to strengthen the importance of the assessment process to ensure the fairness and reasonableness of the performance appraisal. It can be said that the purpose of performance appraisal in enterprises is not only to do a good job in the management of employees but also to improve the business 
level of employees as an important management goal. Therefore, human resources managers can also give targeted training guidance according to the actual assessment situation of employees to improve their working ability and comprehensive quality. Therefore, enterprise managers also need to clarify the purpose of the performance appraisal.

Enterprises can build a reasonable performance appraisal system according to the existing market conditions and their own development, which can lay a good foundation for the follow-up performance appraisal. In the process of building the performance appraisal system, enterprises are required to clarify the status qua of other management systems outside of human resource management, to ensure mutual promotion and compatibility among the management systems and to avoid isolation of the performance appraisal system in the application process.

The fairness of performance appraisal is an important principle to play the role of performance appraisal, so the enterprise also needs to fully follow the principle of fairness in the process of construction and implementation of the performance appraisal system, so as to avoid the influence on the employees' work emotion and protect the employees' work enthusiasm. In the process of performance appraisal, managers are required to disclose the evaluation criteria of performance appraisal to employees, which can not only make employees clear the work requirements of their positions but also enable employees to clarify their own shortcomings in the work process and correct them by ways of reference and comparison so that the role of performance appraisal can be fully played. In addition, there are more performance appraisal methods in the process of performance appraisal, and the scope of application of different appraisal methods also has certain differences, which also requires enterprises to combine their own development characteristics based on a reasonable choice of performance appraisal methods, to ensure the fairness of the appraisal process to achieve the expected performance appraisal effect.

\section{Conclusions}

This paper provides two algorithms for multilayer classification based on supporting SVM. First, the same learned subclass method is used for text sorting subclass acquisition, and then, the class of the text is determined. Second, a hemispherical support SVM is used to find the smallest hypersphere in the feature space that contains the most text of the class and segment the class from other texts. HEM can anlayse the actual assessment of employees to give targeted training guidance to improve the work ability of employees and comprehensive quality. Therefore, enterprise managers also need to clarify the purpose of performance appraisal so that they can give full play to the role of performance appraisal in the financial management work.

\section{Data Availability}

The dataset used in this paper are available from the corresponding author upon request.

\section{Conflicts of Interest}

The authors declared that they have no conflicts of interest regarding this work.

\section{Acknowledgments}

This work was supported by National Social Science Fund Project: Research on Inter-organizational Knowledge Sharing Behavior and Its Dynamic Incentive Mechanism in Differentiation Context, under Grant no. 20BGL126.

\section{References}

[1] B. Walmsley, "A reflective perspective on the challenges facing research-led teaching in the performing and creative arts," Arts and Humanities in Higher Education, vol. 12, no. 2-3, pp. 222-233, 2013.

[2] Q. J. Zhu and G. H. Su, "Research on the human resources performance management based on the strategic direction data mode analysis," Applied Mechanics and Materials, vol. 687-691, pp. 4560-4563, 2014.

[3] D. R. Recupero, M. Dragoni, V. Presutti, A. Gangemi, and A. G. Nuzzolese, "Sentilo: frame-based sentiment analysis," Semantic Web Evaluation Challenges, vol. 7, no. 2, pp. 211222, 2015.

[4] A. H. Y. Hon, "Shaping environments conductive to creativity: the role of intrinsic motivation," Cornell Hospitality Quarterly, vol. 53, no. 1, pp. 53-64, 2012.

[5] T. Xie, C. Zhang, Z. Zhang, and K. Yang, "Utilizing active sensor nodes in smart environments for optimal communication coverage," IEEE Access, vol. 7, pp. 11338-11348, 2018.

[6] A. Zafra and S. Ventura, "G3P-MI: A genetic programming algorithm for multiple instance learning," Information Sciences, vol. 180, no. 23, pp. 4496-4513, 2010.

[7] L. R. Bliss, S. B. Caley, and R. Pettignano, "An interdisciplinary collaborative approach to wellness: adding lawyers to the healthcare team to provide integrated care for patients," The International Journal of Health, Wellness and Society, vol. 1, no. 2, pp. 129-140, 2011.

[8] H. Matimbwa and O. S. Masue, "Usage and challenges of human resources information system in the Tanzanian public organizations," Journal of Human Resource Management, vol. 7, no. 4, pp. 131-137, 2019.

[9] L. Zhang, C. Liu, C. J. Davis, D. S. Solomon, T. B. Brann, and L. E. Caldwell, "Fuzzy classification of ecological habitats from FIA data," Forest Science, vol. 50, no. 9, pp. 117-127, 2004.

[10] D. C. Wilson, L. Rodic, A. Scheinberg, C. A. Velis, and G. Alabaster, "Comparative analysis of solid waste management in 20 cities," Waste Management \& Research: The Journal for a Sustainable Circular Economy, vol. 30, no. 3, pp. 237-254, 2012.

[11] F. Xue and J. Zhao, "Application calibration based on energy consumption model in optimal design of green buildings," Advances in Materials Science and Engineering, vol. 2021, no. 4, 9 pages, Article ID 5360443, 2021.

[12] S. Sarkar, P. Mallick, and A. Banerjee, "A real-time machine learning approach for sentiment analysis," Advances in Intelligent Systems \& Computing, vol. 339, pp. 705-717, 2015.

[13] J. C. Vidal, M. Mucientes, A. Bugarín, and M. Lama, "Machine scheduling in custom furniture industry through neuroevolutionary hybridization," Applied Soft Computing, vol. 11, no. 2, pp. 1600-1613, 2011. 
[14] Y. Jiang, D. Wang, and Q. Zeng, "Can founders'dual rolesfacilitate innovation?-from the perspective of founders' R\&D network characteristics," Journal of Business Economics and Management, vol. 22, no. 5, pp. 1288-1307, 2021.

[15] C. Zhang, T. Xie, K. Yang et al., "Positioning optimisation based on particle quality prediction in wireless sensor networks," IET Networks, vol. 8, no. 2, pp. 107-113, 2019.

[16] A. Rai, B. Minsker, W. Sullivan, and L. Band, "A novel computational green infrastructure design framework for hydrologic and human benefits," Environmental Modelling \& Software, vol. 118, pp. 252-261, 2019.

[17] R. Xia, F. Xu, C. Zong, Q. Li, Y. Qi, and T. Li, "Dual sentiment analysis: considering two sides of one review," IEEE Transactions on Knowledge and Data Engineering, vol. 27, no. 8, pp. 2120-2133, 2015.

[18] J. Martínez-Ferrero, S. Banerjee, and I. M. García-Sánchez, "Corporate social responsibility as a strategic shield against costs of earnings management practices," Journal of Business Ethics, vol. 133, no. 2, pp. 305-324, 2016.

[19] J. Bajo, M. L. Borrajo, J. F. De Paz, J. M. Corchado, and M. A. Pellicer, "A multi-agent system for web-based risk management in small and medium business," Expert Systems with Applications, vol. 39, no. 8, pp. 6921-6931, 2012.

[20] J. M. Trauth, P. I. Documét, M. Hawk, and N. Blais, "Aligning a departmental $\mathrm{D}(\mathrm{R}) \mathrm{PH}$ program with the new ASPH competencies," Public Health Reports, vol. 126, no. 2, pp. 294-298, 2011.

[21] R. Brito and L. Oliveira, "The relationship between human resource management and organizational performance," Entific Management Research, vol. 13, no. 3, pp. 90-110, 2005.

[22] B. Jamal Ali and G. Anwar, "The mediation role of change management in employee development," Nternational Journal of English Literature and Social Sciences, vol. 6, no. 2, pp. 361-374, 2021.

[23] D. Wu, C. Zhang, L. Ji, R. Ran, H. Wu, and Y. Xu, "Forest fire recognition based on feature extraction from multi-view images," Traitement du Signal, vol. 38, no. 3, pp. 775-783, 2021.

[24] B. J. Ali and G. Anwar, "Intellectual capital: a modern model to measure the value creation in a business," International Journal of Engineering, Business and Management, vol. 5, no. 2, pp. 31-43, 2021.

[25] B. J. Ali and G. Anwar, "Marketing strategy: pricing strategies and its influence on consumer purchasing decision," International journal of Rural Development, Environment and Health Research, vol. 5, no. 2, pp. 26-39, 2021.

[26] L. Wang, C. Zhang, Q. Chen et al., "A communication strategy of proactive nodes based on loop theorem in wireless sensor networks," in Proceedings of the 2018 Ninth International Conference on Intelligent Control and Information Processing (ICICIP), pp. 160-167, IEEE, Wanzhou, China, November 2018.

[27] B. J. Ali, G. Anwar, B. Gardi et al., "Business communication strategies: analysis of internal communication processes," Journal of Humanistic Education and Development, vol. 3, no. 3, pp. 16-38, 2021.

[28] M. Úbeda-García, E. Claver-Cortés, B. Marco-Lajara, and P. Zaragoza-Sáez, "Corporate social responsibility and firm performance in the hotel industry. The mediating role of green human resource management and environmental outcomes," Journal of Business Research, vol. 123, pp. 57-69, 2021.

[29] P. Liu, W. Qingqing, and W. Liu, "Enterprise human resource management platform based on FPGA and data mining,"
Microprocessors and Microsystems, vol. 80, Article ID 103330, 2021.

[30] I. A. Elshaer, A. E. E. Sobaih, M. Aliedan, and A. M. S. Azazz, "The effect of green human resource management on environmental performance in small tourism enterprises: mediating role of pro-environmental behaviors," Sustainability, vol. 13, no. 4, Article ID 1956, 2021.

[31] A. Tahiri, I. Kovaci, and A. Krasniqi, "Appraisal of human resource management, performance management and employee performance by SME managers in kosovo," International Journal of Economics \& Business Administration (IJEBA), vol. 9, no. 1, pp. 292-302, 2021.

[32] A. Alvis, H. S. Villada, and D. C. Villada, "Effect of the time and temperature fried on the sensory characteristics of yam (Dioscorea alata)," Informacion Tecnologica, vol. 19, no. 5, pp. 19-26, 2008.

[33] R. Kumar and J. C. Usunier, "Management education in a globalizing world: lessons from the French experience," Management Learning, vol. 32, no. 3, pp. 363-391, 2004.

[34] S. Rynes, "Academy of management journal editors' forum on the research-practice gap in human resource management editor's foreword: tackling the "great divide" between research production and dissemination in human resource management," Academy of Management Journal, vol. 50, no. 5, pp. 985-986, 2007.

[35] D. K. Datta, X. Liang, and M. Musteen, "Strategic orientation and the choice of foreign market entry mode," Management International Review, vol. 49, no. 3, pp. 269-290, 2009.

[36] A. Fayolle, F. Liñán, and J. A. Moriano, "Beyond entrepreneurial intentions: values and motivations in entrepreneurship," The International Entrepreneurship and Management Journal, vol. 10, no. 4, pp. 679-689, 2014. 